\title{
Cartografia de um encontro: Sophia e Cecília
}

\author{
Eduardo Silva Russell \\ Pontifícia Universidade Católica do Rio de Janeiro
}

\begin{abstract}
Resumo
Sophia de Mello Breyner Andresen, além de poemas, escreveu uma série de ensaios que, embora não estejam ainda copilados em livro, mostram a proximidade de sua voz com a de outros autores em língua portuguesa, como Cecília Meireles. O encontro desta com aquela, que nunca se deu fisicamente, não deixou de acontecer e de ser celebrado na poesia, que permitiu, sobretudo para Sophia, a reflexão sobre o seu próprio lirismo.
\end{abstract}

Palavras-chave: poesia portuguesa do século XX; Sophia de Mello Breyner Andresen; Cecília Meireles; modernidade; crítica de poesia; Brasil; Portugal.

\begin{abstract}
Sophia de Mello Breyner Andresen wrote poems and also wrote a series of essays that, although not yet compiled in book, are able to show the proximity of its voice with that of other authors in Portuguese Language, like Cecília Meireles. The Brazilian poet, who never met physically with the Portuguese, crossed their poetics, allowing, especially for Sophia, the reflection on her own lyricism.
\end{abstract}

Keywords: Portuguese poetry of the twentieth century; Sophia de Mello Breyner Andresen; Cecília Meireles; modernity; poetry criticism; Brazil; Portugal.

Recebido em: 27/05/19

Aprovado em: 06/07/19

O texto cujo título é "A poesia de Cecília Meireles", apesar de conciso, apresenta algumas leituras que Sophia faz da artista e de sua obra poética, abrindo caminho para que se possa discutir não só a poética de Cecília, mas também a de Sophia, que se constrói a partir da interação de suas vozes. A atenção que esta dedica à arte brasileira, dentro do que se quer analisar, mostra-se como um dos caminhos pelos quais é possível ter acesso à produção literária da poeta portuguesa.

Em minha dissertação de mestrado, Sophia de Mello Breyner Andresen, leitora de poetas, mostrei como os ensaios dedicados a outros escritores são, em parte, a expressão de suas marcas poéticas em tempos variados, que acompanham os temas e interesses de seus livros de poemas. Em Portugal, a autora de Dual sempre esteve atenta à literatura e à história do Brasil. Uma rápida análise do índice de sua obra poética, por exemplo, nos coloca diante de títulos que 
reforçam o interesse da poeta pelos que estão no além-mar. O capítulo "Brasil ou do outro lado do mar", do livro Geografia, em que estão presentes os poemas "Descobrimento", "Manuel Bandeira", "Brasília" e "Poema de Helena Lanari", além de outros, como "Carta de Natal a Murilo Mendes", do livro O nome das coisas, são exemplos.

Nos contornos do Brasil, os olhos de Sophia também olharam para Cecília Meireles, a quem, por infortúnios, não pôde conhecer pessoalmente, como conta a João Almino, escritor e diplomata brasileiro que a entrevistou:

Aconteceu uma coisa, que não foi um encontro, foi mais um desencontro, porque nesse tempo eu estava muito metida nas lutas contra o salazarismo, e a Cecília estava em casa de um escultor que era muito boa pessoa, mas tinha uma mulher - ela já deve ter morrido - que lhe disse que eu era uma perigosa, e isso fez um bocado de confusão. Eu consegui... organizamos com os melhores escritores portugueses, com o Casais, o Jorge de Sena etc., uma sessão de homenagem à Cecília. E a Cecília não apareceu. E depois soubemos que lhe tinham dito que éramos uma organização de comunistas. $\mathrm{E}$ eu fui à sessão e li os poemas da Cecília com o mesmo entusiasmo. Quando daí a dois dias o amigo da Cecília que lá estava disse a ela que a sessão tinha sido muito bonita, a Cecília ficou arrependidíssima, porque tinha feito uma figura pouco simpática. A Cecília era muito bonita. Mas era uma mulher muito dominada. (ALMINO, 1999)

Aquilo que foi o motivo de desencontro em terras portuguesas não impediu a celebração do encontro de suas vozes na poesia. No ensaio "A poesia de Cecília Meireles" é possível ver reflexões acerca da produção artística brasileira, particularmente sobre a autora de "Mar absoluto", percebendo nesta uma espécie de eco poético através do Atlântico.

Ao interpretar a cartografia deste encontro, inevitavelmente, penso a relação entre Portugal e Brasil, ainda pouco explorada nos estudos comparativos de literatura, mas de grande relevância para o aprofundamento das discussões acerca das obras dos mais variados autores. Apesar de ser evidente o afastamento geográfico entre os países, o que atrapalha a aquisição e divulgação das artes produzidas entre o além e o aquém-mar, as dificuldades geradas pelos hiatos que se formam entre as publicações de poemas e afins não diminuem as relações que se constroem entre os poetas daqui e os de lá, uma vez que há no processo de leitura comparativa a possibilidade de renovação de teorias sobre determinadas obras e artistas, expandindo-se, assim, o território da análise crítica e também os limites estabelecidos à prática poética de um autor.

No que diz respeito aos estudos andresenianos, existem diversos trabalhos sobre os poemas da autora, bem com são diversos os diálogos realizados entre os textos dela e os de outros poetas. A tese de Jussara Rezende (2006), defendida na Universidade de São Paulo que estuda Sophia e Cecília Meireles - e, na Pontifícia Universidade Católica, as teses de Sophia Silva e de Rita Barbosa analisam, respectivamente, a relação entre Sophia e Adília, e a interface entre a poesia e a política nas obras da poeta. A tese de Marcia Barbosa (2011) 
verifica a relação que apresenta a obra andreseniana com Camões, Cesário Verde e Fernando Pessoa. Esses estudos são exemplos, aqui no Brasil, das leituras que já foram realizadas sobre os textos deixados por Sophia Andresen. Nesses trabalhos, embora alguns ensaios de Sophia apareçam, o foco dos estudos majoritariamente é dado aos poemas. Proponho, pois, um foco sobre os ensaios, porque esses textos se revelaram fontes de grande relevância para os estudos que vêm sendo feitos sobre a autora, sendo possível examinar a forma como Sophia interage com Cecília, por exemplo.

Um breve olhar para a vida de artista de Cecília Meireles nos mostra que as idas da autora a Portugal eram frequentes, fato que era um facilitador para a divulgação de seus textos. As primeiras publicações de seus livros de poemas foram anteriores às de Sophia. Esta, evidentemente, leu os poemas daquela de modo a apropriar-se de versos e títulos. O poema "Mar absoluto", de Cecília Meireles, por exemplo, certamente inspirou o livro intitulado Mar novo, de Sophia de Mello Breyner, haja vista a marcante relação entre as palavras e os temas. Tal poema, aliás, é citado e analisado no ensaio "A poesia de Cecília Meireles".

Como ponto primeiro dessa reflexão, é interessante observar que diferentes leituras incidem sobre determinadas obras e, por esse motivo, perspectivas e momentos díspares moldam, torcem e contorcem determinadas ideias engessadas sobre alguma arte a partir de novas possibilidades e ressignificações que podem ser exploradas, propiciando, assim, múltiplas leituras e um não esvaziamento delas. Esclarece-se que isso é ressaltado devido ao fato de que as fronteiras entre Sophia de Mello Breyner Andresen e Cecília Meireles já foram reduzidas por alguns estudos acadêmicos. ${ }^{1}$ Porém, é possível, ainda assim, apresentar um ponto de vista novo, a partir de uma nova óptica, que, nesse caso, tem como propósito particular o de exibir a maneira como a autora portuguesa se ligou à autora brasileira em seus poemas e ensaio, explorando, com isso, os fatores que motivaram a leitura desta por aquela e, também, a forma como essa leitura foi feita.

A atração de Sophia pelo Brasil não se restringe somente aos poetas, arquitetura ou natureza. Em uma entrevista concedida ao jornal Contemporâneo, de 19 de março de 1989, Sophia mostrava a sua atração e respeito pela língua portuguesa e pela poesia brasileira:

Eu tenho uma grande admiração pelo J. C. de Melo como poeta, acho-o um poeta extraordinário, um dos maiores escritores vivos no mundo inteiro. Se não fosse um escritor de língua portuguesa, já tinha ganho três prémios Nobel. Mas ele é brasileiro... As línguas dominantes são línguas dos países ricos e muito industrializados, onde as pessoas estão, aliás, a perder a fala. Nesses países as crianças já não sabem ouvir uma história, as pessoas estão a perder muito certas qualidades de comunicação... (ANDRESEN, 1989, p. 12)

\footnotetext{
${ }^{1}$ BACKES (2009), REZENDE (2006).
} 
Além disso, na rica análise do "Poema de Helena Lanari”, feita por Eucanaã Ferraz (2011), o professor atenta para os versos:

Gosto de ouvir o português do Brasil

Onde as palavras recuperam sua substancial total

Concretas como frutos nítidas como pássaros

Gosto de ouvir a palavra com as suas sílabas todas

Sem perder sequer um quinto de vogal

Quando Helena Lanari dizia 'coqueiro'

O coqueiro ficava muito mais vegetal" (ANDRESEN, 2011, p. 517, apud FERRAZ, 2011, p. 33)

Em análise, Ferraz ressalta a amizade e ternura com a qual Sophia, olhando para a linguagem, repara na terra e no idioma. Ela, perceptivelmente, declara-se admiradora do português falado no Brasil, como mostra o professor, quando diz que

Os versos, pelo menos à primeira vista, não apresentam "as palavras" como entidade subjetivada ou em sua qualidade poética. Antes, localiza-as numa atividade específica: a fala. Ou, ainda, longe de toda abstração, o poema mostra-as como matéria do funcionamento linguístico no discurso oral. Assim, assistimos, inicialmente, a uma espécie de exame da fonação, a emissão apenas, considerada sob o aspecto articulatório e acústico, sem se levar em conta o valor da forma linguística, reunião de significante e significado. Dizer que o português do Brasil - e não há dúvidas de que aqui se faz uma comparação com o português de Portugal — as palavras são articuladas "com suas sílabas todas/ sem perder sequer um quinto de vogal", donde a recuperação de uma "substância fônica total" é modo singular de dizer que a fonologia analisaria em termos de descrição dos fonemas em suas variantes posicionais e combinações. O "ouvido" de Sophia, digamos assim, confirma observações de cunho científico - a realização (fonética) anterior da vogal brasileira em oposição à realização mais recuada, mais central, do português europeu — num poema onde o ponto de partida é tão explícito e asseverado quanto singelo: "gosto de ouvir". (FERRAZ, 2001, p. 32)

Desse modo, mesmo com as várias reflexões que possam ser feitas sobre o poema e a crítica, interessa-nos apontar que esse "gostar de ouvir", se levado às últimas consequências, pode ser entendido para além do simples gesto de apreciar a língua ou a cultura. Na verdade, a relação que se pode estabelecer, nesse momento, tem a ver também com as particularidades que se fazem ver no universo poético andreseniano. Se a ela importa as falas e os versos brasileiros, as referências que a conduzem são orientadas por individualidades, que a aproximam dos elementos sobre os quais deseja falar. $\mathrm{O}$ que se quer dizer é que as motivações pessoais que estimularam a escrita da autora se escoram em uma espécie de identificação com o objeto que é estudado.

No que diz respeito ao ensaio “A poesia de Cecília Meireles”, nota-se que, apesar de aparentemente ser apenas um texto crítico, possui um quê artístico, justamente por apresentar 
forte subjetividade, percebida nas escolhas vocabulares e até mesmo na forma como as considerações levantadas sobre a escritora brasileira são realizadas.

No ensaio, o fluxo de leitura é, de fato, ondulante, a escrita não é feita de modo esquemático e linear. A experiência da escrita ensaística, aqui, é feita para ser uma viagem, uma experiência. Por isso, as palavras não pretendem classificar ou esgotar o material de estudo, a dicção de Cecília Meireles. Na verdade, o texto convida à reflexão, cedendo espaço, inclusive, para que o leitor participe de uma navegação sem um rumo preestabelecido. A experiência da navegação é o que importa. No ensaio de Sophia, é dito:

A poesia de Cecília Meireles é uma poesia construída sobre dualidades. É um equilíbrio de oposições e uma harmonia de contrários.

É uma poesia ao mesmo tempo clássica e romântica, objectiva e subjectiva, serena e desesperada, intemporal, desligada, distante e humanamente cheia de paixões e lágrimas. (ANDRESEN, 1999, p. 62)

A observação que Sophia faz sobre a poética de Cecília parte da verificação da dualidade sobre a qual a escrita da autora brasileira se funda. As oposições estão entre clássica e romântica; objetiva e subjetiva; serena e desesperada; intemporal, desligada, distante e humana; paixões e lágrimas. As oposições listadas, ao longo do texto, encontram pares, formando grupos maiores em que se agregam, em grandes grupos, as dualidades da poética de Cecília. Os grandes grupos onde ocorrem os encontros são o da poesia clássica e o da poesia romântica. Naquela, juntam-se a objetividade, serenidade; nesta, o desespero, a paixão, a subjetividade.

No classicismo de Cecília Meireles há um eco de Camões. Isto não quer dizer que ela imite Camões nem mesmo que tenha sido particularmente influenciada por Camões. Mas Camões encontrou a objectividade da língua portuguesa, com uma tal exactidão que todo o poeta de inspiração clássica fatalmente, embora involuntariamente se encontra com ele. $[\ldots]$

Mas, ao mesmo tempo que é profundamente clássica a poesia de Cecília Meireles é também profundamente romântica. Clássica pelo equilíbrio da sua forma, pela nitidez das suas palavras, pela claridade e transparência da sua linguagem e pela serenidade e lucidez da sua atitude em frente do mundo, a poesia de Cecília é romântica pela ressonância nocturna da sua voz, pelo seu subjectivismo, pelo seu panteísmo, pela sua ligação com o sonho, pelo aspecto livre e fantástico das suas imagens. (ANDRESEN, 1999, p. 62-63)

Sophia ilustra as suas afirmações com poemas de Cecília Meireles, que não são examinados pela ensaísta. Apenas breves comentários, como "Eis aqui um poema em que o classicismo de Cecília Meireles é particularmente evidente" (ANDRESEN, 1999, p. 62) e "Eis aqui um poema que exprime o seu romantismo" (ANDRESEN, 1999, p. 63). O ensaio, assim, não exaure a leitura que se faz de Cecília. A estratégia de interpretação é feita em termos de um jogo de leitura, uma vez que o leitor é convidado para a construção da análise, não dando 
um fim ou uma interpretação pronta da autora, mas propondo uma aventura - aventura essa com que Sophia se encontra e enfrenta, como é possível ver em um poema do livro Coral, cujos versos "Ia e vinha/ E a cada coisa perguntava/ Que nome tinha." (ANDRESEN, 2011, p. 255) parecem encontrar-se com Cecília, que, nas palavras de Sophia, "é um poeta subjectivo na medida em que ela se busca a si própria através de tudo, na medida em que ela é alguém que vai: 'Dando e buscando sempre a sua própria imagem'” (ANDRESEN, 1999, p. 64).

Sobre esses versos, não se sabe ao certo se a pessoa do discurso é a primeira ou a terceira. $\mathrm{Na}$ frase, sabe-se que é a terceira pessoa. O trabalho com a linguagem não é - nem precisa ser - livre de ambiguidades. Dessa forma, pouco importa desvendar se é o eu ou se é o ele que "a cada coisa perguntava/ Que nome tinha", uma vez que é possível observar que é no exercício da escrita que o artista está "buscando sempre a sua própria imagem". A busca e a aventura no (e pelo) texto não se esgotam em si, portanto, mas participam da interação e da atividade reflexiva que ruma para um centro de infinitas possibilidades que descentraliza a escrita, propondo que se pense o próprio rumo, isto é, a própria escrita e, assim, as próprias poetas.

Aqui, parece-me propício lembrar que o ensaio enquanto gênero está, historicamente, situado em um espaço sinuoso, turvo, indefinido. $\mathrm{O}$ ato de ensaiar, como o próprio nome sugere, indica a ação de testar, de experimentar, de definir os contornos, preliminarmente, para o produto final. Para o teatro e para a escrita, o ensaio possui tanta (ou mais) importância que a materialização da obra final, já que é a dedicação ao ensaio a responsável pela qualidade ou não da apresentação que se pretende fazer. A semântica que o substantivo "ensaio" carrega, de certa forma, se soma com a posição que tem o gênero textual, uma vez que a sua própria classificação é flutuante, inclassificável, digamos assim. Não se podem definir caminhos para a escrita de um ensaio. As leis que outros textos, como monografias, teses, tratados e afins possuem não se aplicam ao ensaio, como nos adverte o professor João Barrento, que explica que "cada ensaio é um texto singular, a que nunca se conseguirá chegar com uma sistemática de géneros. $O$ sistema tem o terror do aporético, o ensaio vive paredes meias com a aporia" (BARRENTO, 2010, p. 27). Pode-se dizer que estamos diante de um gênero textual sem leis. Ensaiar não exige acertos e regras rígidas. Ensaiar exige tensionar e exercitar as possibilidades.

Em "A poesia de Cecília Meireles", a dualidade sobre a qual Sophia fala a respeito da poesia de Cecília Meireles é também observada por Helena Malheiro no livro $O$ enigma de Sophia, quando analisa a obra andreseniana. A pesquisadora, logo no início do seu estudo, aponta:

Toda a obra de Sophia de Mello Breyner Andresen é uma incessante busca da "inteireza" das coisas, dos seres e do universo. Incessante navegação de procura e de descoberta de si e do Outro, numa permanente tentativa de se explicar e de explicar o mistério do mundo que a rodeia, avançando pelo mar adentro como quem avança pela alma, numa viagem vertical, mítica viagem de conhecimento e de procura da unidade perdida dentro e fora de si, para chegar à essência do Ser. [...] 
Partindo sempre de uma crucial dicotomia da qual germina e estrutura, a obra da poetisa desenvolve-se em permanência entre dois polos opostos. Nascida da sombra rouca do Caos, da dissolução informe e dos seus medos e pavores, ela encaminha-se sempre, no entanto, para a luminosa unidade de uma aliança com o esplendor do universo, onde a palavra diz o espanto e a "veemência do visível". (MALHEIRO, 2008, p. 20)

As palavras de Helena Malheiro sobre Sophia parecem espelhar as palavras desta sobre Cecília. A autora de "Mar novo", na posição de crítica, não tenta descobrir o sentido único da obra ceciliana, nem mesmo Helena Malheiro faz isso em relação à poeta portuguesa. A visualização das dualidades que recaem sobre as poéticas das autoras mostra que, no processo de leitura que se faz do outro, Sophia não tem como objetivo examinar de maneira maniqueísta a poesia. Na verdade, percebe-se que a crítica possibilita a ampliação e desdobramento da obra. O ensaio de Sophia de Mello Breyner seria aquilo que Walter Benjamim articula em $O$ conceito de crítica de arte no Romantismo alemão, quando expõe:

A tendência imanente da obra e o correspondente critério de sua crítica imanente são a reflexão que está em sua base e que se manifesta em sua forma. Esta reflexão, no entanto, na verdade não é tanto o critério do julgamento, mas, antes de mais nada e em primeira linha, o fundamento de uma crítica totalmente outra, não posta como julgadora, cujo centro de gravidade está não na estimação da obra singular mas na exposição de suas relações com todas as demais obras e, finalmente, com a Ideia de arte. (BENJAMIN, 2002, p. 83)

No papel de crítica, Sophia não propõe um acabamento, mas um complemento, uma viagem nos caminhos trilhados por Cecília. O ensaio, então, como gênero textual, aproveitandome da metáfora, seria um mar, um oceano, talvez, cujas precisões são ondulantes. É estratégico para a navegação em que se lança a autora de "No tempo dividido", porque, como nas palavras de Theodor Adorno,

O ensaio exige no menos, porém mais que o procedimento por definições, interação dos conceitos no processo de experiência espiritual. Nesta, eles não constituem nenhuma continuidade operacional e o pensamento não avança unilateralmente, mas os momentos se entretecem como num tapete. (ADORNO, 2003, p. 177)

A imagem do tapete, metáfora da forma pela qual o ensaio se entretece, acaba por somarse à análise proposta pelos românticos alemães acerca da função da crítica. O ensaio e a crítica são constituídos por camadas, por partes que se ligam para ampliação da arte, uma vez que

"a obra é incompleta", como afirma Benjamin, já que, por si mesma, não é absoluta. Só que a falta é positiva para os primeiros românticos, já que "só o incompleto... pode levar-nos mais adiante", enquanto "o completo é apenas fluido", afirma Novalis. 
Daí a centralidade da crítica, apareça ela onde for, com quem for e como for não é apenas fruição estética da obra que está em primeiro plano, e sim correspondência a ela na linguagem crítica, que só ocorre porque a obra ainda não é completa por si. (DUARTE, 2011, p. 97)

Quando Sophia diz que "É impossível isolar e exemplificar todas as dualidades que há na poesia de Cecília Meireles" (ANDRESEN, 1999, p. 70), a crítica construída é envolvida por fundamentos teóricos e filosóficos de estudos que formaram a autora enquanto poeta-crítica. Aliás, basta olhar a quem Sophia dedicou ensaios e poemas para concluir que a sua formação como leitora é vasta. Quando diz que não se pode reduzir a obra de um autor a observações e conclusões particulares, a poeta nos dá indícios de seu entendimento literário, de sua percepção lírica. Mesmo admitindo que a escrita de Cecília não pode ser isolada, Sophia a analisa a partir de perspectivas particulares, atentando para a natureza e para a plasticidade dos versos, particularmente. Olhando para esses mundos, Sophia revela que a riqueza da poética de Cecília não se reduz apenas à sua visão e à sua análise. Portanto, o que somos capazes de verificar no ensaio é aquilo que em Cecília interessa mais à Sophia. A forma como aquela é lida faz com que se veja e pense sobre esta. Assim, mesmo que, aparentemente, o foco da escrita esteja em Cecília, o que emerge no ensaio são as diversas leituras, as experiências de vida que atravessam a produção andreseniana.

Torna-se evidente, assim, a ligação que Sophia tem com o Romantismo alemão. Sophia é uma autora moderna, e a modernidade se ergue, entre outros pilares, pela autocrítica e reflexão. Poemas e ensaios dedicados a Hölderlin, por exemplo, poderiam, ainda, ilustrar a atenção que ela tem a tal movimento literário; no entanto, o que quero ressaltar é o fato de ser possível enxergar nos textos de caráter crítico da autora (e aqui não falamos apenas dos ensaios, mas também dos poemas) procedimentos e técnicas que remetem aos procedimentos e técnicas do Romantismo alemão.

Durante do século XX, em Portugal, os poetas que escreveram na corrente das décadas posteriores aos anos 1920 se deparam com diversas perguntas, entre as quais: "Qual o papel da arte em tempos de fascismo?", “Como fazer poesia depois de Fernando Pessoa?" Se o exercício da crítica é mediado pela autorreflexão e, por assim ser, pela autocrítica, isso, por sua vez, traz à tona, no que diz respeito à Sophia, algo caro à sua poética: na tentativa de se conhecer a si mesma, na tentativa de conquistar um lugar para si e para a sua poesia no contexto português, a busca pelo autoconhecimento pode ser verificada como uma das forças que movem a escrita da poeta.

Em $O$ conceito de crítica de arte no Romantismo alemão, de Walter Benjamim explica:

Ser crítico implica elevar o pensamento tão acima de todas as conexões a tal ponto que, por assim dizer magicamente, da compreensão da falsidade das conexões, surgiria o conhecimento da verdade. Nesta significação positiva o procedimento crítico adquire uma afinidade muito próxima com o procedimento reflexivo. (BENJAMIM, 2002, p. 56) 
E, ainda, continua dizendo que

Onde não há autoconhecimento, não há absoluto nenhum conhecer, onde há autoconhecimento, a correlação sujeito-objeto está superada, ou, se quiser: dá-se um sujeito sem objeto-correlato. Apesar disso, a realidade não forma um agregado de mônadas fechadas em si que não podem ter nenhuma relação real umas com as outras. Muito pelo contrário, todas as unidades no real, fora o absoluto, são apenas relativas. Elas estão tão pouco fechadas nelas mesmas e privadas de ligação que, antes, podem, via intensificação de sua reflexão, incorporar mais e mais ao próprio autoconhecimento outras essências, outros centros de reflexão. Este modo de representação romântico diz respeito, entretanto, não apenas aos centros de reflexão individuais e humanos. Não apenas os seres humanos podem estender seu conhecimento via intensificação do autoconhecimento na reflexão, mas, do mesmo modo, as assim chamadas coisas da natureza o podem. Nestas, o processo tem uma ligação essencial com aquilo que geralmente é denominado sem "ser conhecido". Nomeadamente, a coisa, na medida em que aumenta a reflexão em si mesma abrange em seu autoconhecimento outras essências, irradia sobre estas seu autoconhecimento originário. [...] Portanto, tudo aquilo que se apresenta ao homem como seu conhecer de uma essência é reflexo nele do autoconhecimento do pensar nesta mesma essência. Então, não existe um mero ser-conhecido de uma coisa, tampouco, no entanto, a coisa ou a essência está limitada a um mero ser-conhecido apenas através de si. A intensificação da reflexão, antes, supera na coisa os limites entre ser conhecida através de si mesma e através de um outro, e, no médium-de-reflexão, a coisa e a essência cognoscente se interpenetram. (BENJAMIM, 2002, p. 62)

Pensando em Sophia, a busca por respostas parece se ancorar, entre outros fatores, na meditação, na tarefa de pensar e repensar a escrita, a arte, o papel e a missão do artista. Ao concentrar-se em Cecília Meireles, a quem chamo de "objeto de estudo", Sophia Andresen, ao modo dos românticos alemães, se une e confunde com seu objeto. O que Sophia verifica na obra de Cecília retoma interesses que comparecem aos versos de Sophia. No ensaio "A poesia de Cecília Meireles", por exemplo, ela diz que

A objectividade de Cecília Meireles está na forma real e exacta em que ela nos fala de estrelas, ondas e árvores. Está naquelas imagens dos seus poemas que nos mostram as coisas tais como elas são em si, na sua forma própria e na sua própria natureza. Cecília Meireles é um poeta objectivo porque nos diz que o mar é um "cavalo épico" e uma "anêmona suave". Porque é um poeta que vê as coisas e não um poeta que as sonha. Porque quando ela nos fala do "vento liso", da "clássica luz de Maio", do "desequilíbrio dos oceanos", a natureza nos mostra aquela sua face divina que o homem não the acrescenta pois ela a possui interiormente. (ANDRESEN, 1956, p. 64)

Tal afirmação vai ao encontro do que fala em sua "Arte Poética III":

Sempre a poesia foi pra mim uma perseguição do real. Um poema foi sempre um círculo traçado à roda duma coisa, um círculo onde o pássaro do real fica preso. E se 
a minha poesia, tendo partido do ar, do mar e da luz, evoluiu, evoluiu sempre dentro dessa busca atenta. Quem procura uma relação justa com a pedra, com a árvore, com o rio, é necessariamente levado, pelo espírito de verdade que o anima, a procurar uma relação justa com o homem. (ANDRESEN, 2011, p. 841)

Nos dois fragmentos, salta aos olhos a presença da natureza. Salta aos olhos a forma como a natureza se faz presente na poesia de Cecília e também na de Sophia. Em Poesia primeiro livro de Sophia - , o poema "Cidade" pode ser lido como exemplo da forma como a percepção dos elementos da natureza se constituem na obra da autora.

\section{CIDADE}

Cidade, rumor e vaivém sem paz das ruas,

Ó vida suja, hostil, inutilmente gasta,

Saber que existe o mar e as praias nuas,

Montanhas sem nome e planícies mais vastas

Que o mais vasto desejo,

E eu estou em ti fechada e apenas vejo

Os muros e as paredes, e não vejo

Nem o crescer do mar, nem o mudar das luas.

Saber que tomas em ti a minha vida

E que arrastas pela sombra das paredes

A minha alma que fora prometida

Às ondas brancas e às florestas verdes. (ANDRESEN, 2011, p. 74)

O eu lírico vê a cidade como um espaço asfixiante, que o afasta dos elementos da natureza. O movimento das ruas faz com o eu lírico não estabeleça a conexão com as ondas, as florestas verdes, com a praia e com o mar. A cidade, nesse aspecto, apesar de ser o lugar da negação, que impede o cumprimento da promessa de entrega à natureza, é também o artifício pelo qual a poeta revela a necessidade de regressar à natureza, à natureza primeira, à natureza sem ação do homem, à natureza que se assemelha à de Schelling.

No livro A filosofia da natureza, Márcia Gonçalves mostra que este filósofo alemão pensa a natureza a partir da ideia de uma matéria auto-organizante. Para ele, afirma a professora:

O princípio da produtividade imanente à natureza é em parte responsável por todo movimento existente, não enquanto primeiro motor contínuo - o que novamente traria a representação linear do movimento - , mas apenas na medida em que esse princípio se encontra em eterna relação dinâmica com seu princípio contrário, que é uma espécie de princípio antiprodutividade ou de obstáculo para a produção. É só a partir dessa dinâmica que o movimento de organização da natureza se fecha em um ciclo infinito. (GONÇALVES, 2006, p. 41) 
Assim, quando Sophia diz que "através de búzios, espaços e brisas, Cecília Meireles busca não o próprio mar real, mas o seu mar, o mar que ela imagina, o mar que lhe é necessário e esse mar que ela chama mar absoluto" (ANDRESEN, 1999, p. 64), percebe-se, dentro do que queremos mostrar, uma reflexão acerca da percepção de uma natureza que é descrita em termos metafóricos, que foge ao detalhamento denotativo e tátil. É essa a natureza - a desligada de uma visualização mensurável e referencial - uma perseguição da sua poesia. O "mar", que é um hipônimo da "natureza", pertence, como é possível notar, ao campo da idealização, da reflexão. A imaterialidade deste mar (a ver a relação que é estabelecida, por meio das figuras de linguagem, entre ele e o "cavalo épico" e a "anêmona suave", por exemplo) é observada pela crítica como um artifício artístico de projeção transcendental. Esse mar deve ser entendido como um ato artístico de criação - a partir da palavra escrita e dita — de um universo paralelo, diferente do universo acidentado do humano.

A atenção e visão de Cecília, segundo Sophia, não compõem, porém, um alheamento da circunstância social, política ou histórica. Pelo contrário, a criação de um mundo novo pode ser entendida como um ato de redenção, uma libertação por meio de um sacrifício, já que a busca pelo novo pressupõe, neste caso, a anulação, ou melhor, a superação de algo imanente. Um espaço ideal é criado a partir do mundo dos homens. Parece ser a dor a condição para a criação e, por isso, então, não se pode dizer que haja nesse gesto de criação um abandono das causas e condições humanas.

$\mathrm{Na}$ “Arte Poética III", aliás, quando Sophia parece delimitar as superfícies por onde o poeta deve caminhar, isso fica mais claro quando ela diz que a natureza está atrelada à justiça e à justeza. Ela diz que "mesmo que o artista escolha o isolamento como melhor condição de trabalho e criação, pelo simples facto de fazer uma obra de rigor, de verdade e de consciência ele irá contribuir para a formação duma consciência comum" (ANDRESEN, 2011, p. 842).

O processo de reflexão do outro é também um processo de transfiguração do eu. Os poemas e interesses de Cecília Meireles são descritos como os mesmos de Sophia de Mello Breyner. Sophia, ao escrever sobre Cecília, descreve-se por meio daquilo que diz sobre a poeta brasileira. $\mathrm{O}$ encontro das duas autoras não foi mero acidente. $\mathrm{O}$ interesse que se faz ver pela obra de Cecília Meireles ultrapassa, na verdade, a definição do que seria um encontro. Não se trata de uma colisão de corpos ou identidades ou mesmo uma procura. Trata-se de uma possível fusão.

Sophia ao ler Cecília acaba por pensar-se a si própria, pensando assim, segundo Silvina Rodrigues Lopes,

sua própria possibilidade [...] de uma relação própria com as coisas e com os outros. Esta relação [que] é quase sempre afirmada como uma questão de percepção. Nesta, o que é considerado verdadeiramente importante não é o resultado, mas o ato de sentir e percepcionar, e sobretudo a colocação do mundo como sensível-perceptível — não o percebido, mas as coisas na sua expectativa, no seu apelo. (LOPES, 2003, p. 52) 
No intuito de clarificar a análise que construirei mais à frente, apresentarei um breve itinerário dos livros publicados por Sophia até os anos 1960, além dos livros Viagem e Mar absoluto, de Cecília Meireles, que são citados pela autora portuguesa no ensaio em questão.

Em 1939, no início da Segunda Guerra Mundial, Cecília Meireles publica o livro Viagem. Neste, a autora apresenta, nas palavras de Miguel Sanches Neto, "uma desleitura deste tópico, colocando a viagem dentro de uma perspectiva antigeográfica, que remete à ideia de transitoriedade". Este autor ressalta, ainda, que "O mundo por onde o eu se move é marcado pela presença de elementos volúveis", entre os quais os "mais recorrentes são flor, água, ondas, espuma, vento, nuvens, música, cigarra e infância”. (NETO, 2001, s./p.)

Em 1944, durante a Segunda Guerra Mundial, Andresen publica seu primeiro livro, intitulado Poesia. A crítica de Silvina Rodrigues Lopes aponta que o livro é marcado por "uma nostalgia e um desejo de regresso à natureza de onde está quase ausente a problemática das relações humanas" (LOPES, 2003, p. 18).

Em 1945, Meireles publica outro livro: Mar absoluto, que foi composto durante os conflitos da Segunda Guerra Mundial. Miguel Sanches Neto diz que a autora continua vendo o mar não só em sua história, como palco de lutas terríveis, mas também a partir de sua gramática de infinito, solitude e melodia.

Com o fim da Segunda Guerra Mundial em 1945, sabe-se que os conflitos ideológicos e bélicos estavam longe de acabar. Em Portugal, a situação ainda era mais agravante por conta do Estado Novo, além das perdas territoriais que o fim da guerra legou ao país, causando, obviamente, problemas sociais devido ao agravamento da instabilidade financeira que se instaurou. No entanto, nem por isso os poemas dos livros Dia do mar (1947), Coral (1950), No tempo dividido (1954) e Mar novo (1958), de Sophia, deixaram de conceder à natureza, nas palavras de Maria de Lourdes Belchior, os "suportes e estruturas da sua demanda da perfeição, da pureza e da harmonia" (1986, p. 49).

Abaixo, os quatro poemas — um de cada livro mencionado acima - servirão para construir uma reflexão sobre a natureza na lírica andreseniana.

1)

\section{Dia do mar}

Jardim Perdido

Jardim perdido, a grande maravilha

Pela qual eternamente em mim

A tua face se ergue e brilha

Foi esse teu poder de não ter fim,

Nem tempo, nem lugar e não ter nome. 
Sempre me abandonastes à beira duma fome.

As coisas nas tuas linhas oferecidas

Sempre ao meu encontro vieram já perdidas.

Em cada um dos teus gestos sonhava

Um caminho de estranhas perspectivas,

E cada flor no vento desdobrava

Um tumulto de danças fugitivas.

Os sons, os gestos, os motivos humanos

Passam em redor sem te tocar,

E só os deuses vieram habitar

No vazio infinito dos teus planos. (ANDRESEN, 2011, p. 144)

2)

Coral

Neste dia de mar e nevoeiro

É tão próximo o teu rosto.

São os longos horizontes

Os ritmos soltos dos ventos

E aquelas aves

Que desdém o princípio das estações

Fizeram ninhos e emigraram

Para que num dia inverso tu as visses.

Aquelas aves que tinham

Uma memória eterna do teu rosto

E voam sempre dentro do teu sonho

Como se o teu olhar as sustentasse. (ANDRESEN, 2011, p. 214)

3)

No tempo dividido

Eu falo da primeira liberdade

Do primeiro dia que era mar e luz

Dança, brisa, ramagens e segredos

E um primeiro amor morto tão cedo

Que em tudo que era vivo se encarnava. (ANDRESEN, 2011, p. 281)

4)

Mar novo

Marinheiro Real

Vem do mar azul o marinho

Vem tranquilo ritmado inteiro 
Perfeito como um deus,

Alheio às ruas. (ANDRESEN, 2011, p. 343)

Uma breve leitura dos quatro poemas selecionados permite que alguns apontamentos sejam realizados a fim de demonstrar uma determinada tônica que perpassa a obra andreseniana particularmente no intervalo de tempo em que os livros foram publicados. Os elementos da natureza não são utilizados apenas para uma ambientação ou determinação de questões climáticas, geografias, circunstanciais; mas, na verdade, podem ser interpretados como mote de uma cena poética, uma vez que a "flor", o "vento", o "mar", a "brisa", as "ramagens", a natureza, de maneira geral, representam metáforas de um projeto artístico que tem como norte o retorno às origens da vida, à ordem do universo estabelecida pela natureza. Emparelhadas a essas palavras, sintagmas como "perdido", alheio", "desdém", "vazio" marcam um contraponto à beleza e à simetria proposta pela máxima platônica, da qual Sophia se serve, que assenta os princípios filosóficos da natureza. A presença da figura humana é vista sob um ponto de vista crítico, porque, aparentemente, por falta de treinamento da escuta, da visão, das sensações, o interlocutor é convidado, direta e indiretamente, a perceber o mundo a sua volta. É preciso se alinhar às coisas da poesia para que a concretização da perfeição proposta pela natureza seja cumprida. O poeta Ruy Belo, no livro Na senda da poesia, comenta:

A minha poesia é, em primeira linha, quotidiana, e refere-se imediatamente a um certo espaço; mas vê esse dia e esse espaço "à transparência", como diria Sophia de Mello Breyner Andresen, e eles funcionam como membro expresso da metáfora que esconde um outro dia e um outro espaço. O homem, tal como a arte o vê, é não só aquilo que é, mas também aquilo que será ou que poderia ser. $(2002$, p. 17)

Isso, portanto, é mais um ponto de contato de Sophia e Cecília. Os seus livros, aparentemente, escapavam das tensões que o momento em que foram produzidos incitava. Porém, só aparentemente mesmo. Miguel Sanches observa em Cecília o que também é dito por Silvina Lopes sobre Sophia: o afastamento das questões cotidianas e a presença da natureza nas obras poéticas das autoras não configuram alheamento, mas sim uma tentativa de dar à poesia um lugar superior, além do mundano. A beleza dos versos e as palavras que os envolvem não são isentas de dor e sentimento de exílio, como observa Silvina a respeito de Sophia, mas podem ser entendidos como um projeto de alcance da transcendência por meio do concreto, terreno.

Sobre Sophia, Maria de Lourdes Belchior diz que sua poesia

aponta para a consciência da dignidade do ser, em última instância, a sua fidelidade à demanda de um tempo não dividido [...] "Para lá das redutoras designações de poesia pura ou poesia comprometida, poesia social ou poesia metafísica, a sua obra revela os desígnios do poeta. $(1986$, p. 41$)$ 
$\mathrm{Na}$ “Arte Poética III", Sophia afirma que "Mesmo que fale somente de pedras ou de brisas a obra do artista vem sempre dizer-nos isto: Que não somos apenas animais acossados na luta pela sobrevivência, mas que somos, por direito natural, herdeiros da liberdade e da dignidade do ser" (ANDRESEN, 2011, p. 841).

Em Cecília Meireles e Sophia, a presença dos elementos que pertencem à natureza em suas obras participam de uma aventura mítica. A natureza é, para as poetas, um caminho para ultrapassar os acidentes humanos para que as suas próprias vidas não sejam um acidente. A portuguesa declara que é preciso que a beleza e a verdade de Cecília Meireles sejam vividas e, só assim, "a limpidez da sua linguagem, a densidade de cada palavra, a exatidão das suas imagens, a nudez do seu pensamento, a serenidade da sua atitude, a ressonância grave e profunda da sua voz" (ANDRESEN, 1956, p. 61) podem revelar "qual é a sua atitude em frente do mundo e qual é a sua atitude frente de si própria" (ANDRESEN, 1956, p. 61).

Em 1960, no ensaio "Poesia e realidade", publicado na revista Colóquio, os caminhos ficam ainda mais claros, quando Sophia apresenta o porquê de "fatalmente, embora involuntariamente, se encontrar com [Cecília]" (ANDRESEN, 1956, p. 61), expondo um claro paralelismo entre aquilo que é dito sobre a poesia de Cecília e aquilo que é dito sobre sua própria concepção poética. A título de exemplo, percebe-se que Sophia considera a poesia da Cecília:

tão naturalmente intemporal e distante, tão diafanamente pura, tão alheia a todos os problemas, acidentais, tão unicamente atenta ao que é essencial e poético que o seu caminho é por vezes um caminho de desligamento, de desprendimento, de pura e solitária desumanização." (ANDRESEN, 1956, p. 68)

Isso, visivelmente, espelha o que Sophia apresenta como sendo sua compreensão sobre o que é poesia, no ensaio "Poesia e realidade", no qual expõe:

Se o poeta procura tanto a solidão, não é só para fugir ao rumor e à agitação, mas também para ver as coisas, quando elas estão sozinhas. A emoção que sentimos ao entrar numa casa deserta ou num jardim abandonado, é a emoção de vermos como as coisas existem, na sua própria realidade, em si. É com esse em si que o poeta quer entrar em relação." (ANDRESEN, 1960, p. 53)

Aparentemente, é como se um elo as unisse de alguma forma. Porém, isto não quer dizer que ela a imite. Na verdade, ao viver a poesia de Cecília, Sophia, de alguma forma, mostra ter sido particularmente atravessada por ela, o que pode ser confirmado no poema "Arte poética", de Sophia, em que se vê uma espécie de citação do poema "Motivo", de Cecília. 
1)

\section{Motivo}

Eu canto porque o instante existe

e a minha vida está completa.

Não sou alegre nem triste:

sou poeta.

Irmão das coisas fugidias,

não gozo nem tormento.

Atravesso noites e dias

no vento. (MEIRELES, 2001, p. 227)

2)

Arte poética

A dicção não implica estar alegre ou triste

Mas dar minha voz à veemência das coisas

E fazer do mundo exterior substância da minha mente

Como quem devora o coração do leão

Olha fita escuta

Atenta para a caçada no quarto penumbroso. (ANDRESEN, 2011, p. 808)

Se pouco importa(m) para o ser poeta ou para a dicção a alegria ou a tristeza, confirmase que "o prazer estético do artista novo emana [do] triunfo sobre o humano" (ORTEGA Y GASSET, 2008, p. 84). Há uma crença de que o afastamento do que há de mais pessoal e íntimo é que pode conduzir à poesia, de que é preciso se despersonalizar para chegar ao poético, fazendo da vida das coisas de que fala a sua própria vida. No entanto,

Não se trata de pintar algo que seja completamente distinto de um homem, ou casa, ou montanha, mas pintar um homem que se pareça o menos possível com um homem, uma casa que conserve de tal o estritamente necessário para que assistamos à sua metamorfose, um cone que saiu milagrosamente do que antes era uma montanha. (ORTEGA Y GASSET, 2008, p. 84)

Isto é, dar "voz à veemência das coisas/ E fazer do mundo exterior substância da [mente]", como diz Sophia em sua "Arte Poética".

Desse modo, Cecília Meireles é um desses nomes que guiaram com infalível presciência Sophia. É com a poesia pura, exata, lisa e inumana de Cecília que Sophia pode falar sobre a sua própria poesia. Assim, ainda que não se possa afirmar categoricamente que a presença da natureza na poesia de Meireles é o que determina, verdadeiramente, o ato de leitura da vida e obra da autora por Andresen, é lícito dizer que a análise desta sobre a utilização do mar, da árvore, do ar, entre outros, por aquela é feita de modo muito similar, o que subsidia a afirmação de que ao pensar a natureza na poética de Cecília, a escritora portuguesa reflete sobre a sua 
própria. A poesia de uma, então, se encontra com a da outra, porque, de fato, o que importa é que, como Sophia diz, "Só em poesia se pode falar em poesia".

\section{Referências}

ADORNO, Theodor Ludwig Wiesengrund. O ensaio como forma. In: . Notas de literatura. São Paulo: Duas Cidades/Editora 34, 2003.

ALMINO, João. A literatura da cisma. Folha de São Paulo, São Paulo, 26 set. 1999. Disponível em: http://www1.folha.uol.com.br/fsp/mais/fs2609199907.htm. Acesso em: nov. 2017.

ANDRESEN, Sophia de Mello Breyner. A poesia de Cecília Meireles. Cidade Nova: Revista de Cultura, São Paulo, IV Série, n. 6, p. 341-352, 1956.

. Poesia e realidade. Revista de Artes e Letras, Lisboa, n. 87, p. 53-54, abr. 1960.

Sophia e o brilho do visível frente a frente. Entrevista. Contemporâneo, 15 mar. 1989. Disponível em http://purl.pt/19841/1/galeria/entrevistas/04.html. Acesso em: 12 ago. 2016. . Obra poética I. Lisboa: Caminho, 1999. . Obra poética II. Lisboa: Caminho, 2011.

BACKES, Karin Lilian Hagemann. Mar de poeta: a metáfora do oceano nas líricas de Cecília Meireles e Sophia Andresen. 2009. 241 f. Tese (Doutorado em Letras) — Pontifícia Universidade Católica, Porto Alegre, 2009.

BARBOSA, Marcia Helena. Navegação sem mapa: a história na poesia de Sophia de Mello Breyner Andresen. In: ALVES, Ida; MAFFEI, Luis (orgs.). Poetas que interessam mais. Rio de Janeiro: Azougue, 2011.

BARRENTO, João. O ensaio em Portugal: sociologia de um gênero sem gênero. In: _. O gênero intranquilo. Lisboa: Assírio e Alvim, 2010.

BELCHIOR, Maria de Lourdes. Itinerário poético de Sophia. Colóquio-Letras, Lisboa, n. 89, p. 36-42, jan. 1986.

BELO, Ruy. Na senda da poesia. Lisboa: Assírio e Alvim, 2002.

BENJAMIM, Walter. O conceito de crítica de arte no Romantismo alemão. Tradução: Marcio Seligmann-Silva. São Paulo: Iluminura, 2002.

DUARTE, Pedro. Estio do tempo: romantismo e estética moderna. Rio de Janeiro: Zahar, 2011

FERRAZ, Eucanaã. Ouvir o poema. In: Relâmpago - Revista de Poesia, Lisboa, n. 9, p. 31-55, 2011.

GONÇALVES, Márcia. A filosofia da natureza. Rio de Janeiro: Jorge Zahar, 2006.

LOPES, Silvina Rodrigues. Escutar, nomear, fazer paisagens. In: - Exercícios de aproximação. Lisboa: Vendaval, 2003. p. 49-75.

MEIRELES, Cecília. Poesia completa. Rio de Janeiro: Nova Fronteira, 2001.

MALHEIRO, Helena. O enigma de Sophia: da sombra à claridade. Alfragide: Oficina do Livro, 2008. 
SANCHES NETO, Miguel. Cecília Meireles e o tempo inteiriço. In: SECCHIN, Antonio Carlos. (org.) Poesia Completa de Cecília Meireles. Rio de Janeiro, Editora Nova Fronteira, 2001, vol. 1.

ORTEGA Y GASSET, José. A desumanização da arte. Tradução: Ricardo Araújo. São Paulo: Cortez, 2008.

REZENDE, Jussara Neves. A simbolização nas imagens poéticas de Cecília Meireles e Sophia de Mello Breyner Andresen: tempo e paisagem. 2006. 167 f. Tese (Doutorado em Letras) Faculdade de Letras da Universidade de São Paulo, São Paulo, 2006.

OLIVEIRA, Rita do Perpétuo Socorro Barbosa de. A poesia de Sophia de Mello Breyner Andresen: o poeta e a participação política. 2010. $141 \mathrm{f}$. Tese (Doutorado em Letras) Pontifícia Universidade Católica do Rio de Janeiro, Rio de Janeiro, 2010.

RUSSELL, Eduardo Silva. Sophia de Mello Breyner Andresen, leitora de poetas. 2017. $150 \mathrm{f}$. Dissertação (Mestrado em Letras) — Instituto de Letras da Universidade Federal Fluminense, Niterói, 2017.

SILVA, Sofia Maria de Sousa. Reparar brechas: a relação entre as artes poéticas de Sophia de Mello Breyner Andresen e Adília Lopes e a tradição moderna. 2007. 160 f. Tese (Doutorado em Letras) - Faculdade de Letras, Pontifícia Universidade Católica do Rio de Janeiro, Rio de Janeiro, 2007.

\section{Minicurrículo}

Eduardo Silva Russell é professor de Língua Portuguesa e Literatura na Escola Parque. É graduado em Letras - Português/Literaturas de Língua Portuguesa — pela Faculdade de Letras da Universidade Federal do Rio de Janeiro, mestre em Estudos de Literaturas pelo Instituto de Letras da Universidade Federal Fluminense e, atualmente, é doutorando no Programa de PósGraduação em Educação pela PUC-Rio. 